\title{
\#POLÍTICA
}

\section{El hambre, la protesta social y la gobernabilidad}

17 DE JULIO, 2020

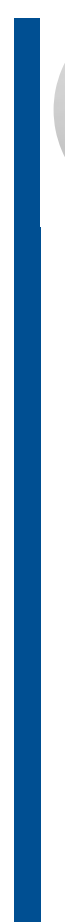

Administrador

Público, Magíster

en Gobierno y

Gerencia Pública.

Académico de la

Facultad de

Ciencias Sociales y

del Grupo de

Investigación

Unidad de Análisis

del Rol del Estado

de Chile, de la

Universidad

Autónoma de Chile

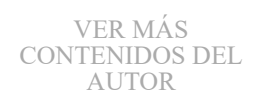

CONTENIDO

ENVIADO

POR

Diego

Durán

Toledo AUTOR
06 | Visitas: $85 \quad A^{-} \quad D$

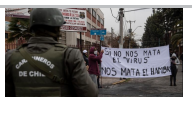

imagen

Las protestas que se han sucedido durante los últimos días, son la representación más gráfica de una ciudadanía que inclusive arriesgando su propia vida en el contexto no solo de crisis sanitaria, sino que en medio de un estado de excepción constitucional, ha salido a las calles para demostrar su descontento con las medidas de salvataje propuestas por el ejecutivo y ejercer mediante la movilización popular una medida de presión ante el parlamento en medio de la discusión del retiro de fondos previsionales durante el estado de catástrofe.

Lo anterior, no solamente se debe al arrastre de una situación política en franco deterioro desde el estallido social de octubre pasado, sino que también a una gestión en materia sanitaria y en especial socioeconómica por parte de la actual administración que no responde a problemáticas estructurales de la ciudadanía.

El veto del ejecutivo al proyecto de ley que imposibilitaba el corte de servicios básicos, la política de endeudamiento propuesta por parte del gobierno como medida apoyo a una clase media con altísimos niveles de morosidad, la oferta de un ingreso enfocado a este sector de la población cuyas especificaciones dejarían sin posibilidad de acceso a un grupo considerable de personas y la negativa de La Moneda de que los afiliados puedan ocupar parte de sus propios fondos de pensiones como una alternativa de autofinanciamiento en esta situación crítica, han generado en la ciudadanía un clima de descontento social inclusive mayor al que motivó la crisis social del 2019. 
\#CIUDADANÍA

President6

Show Me

The

Money

Patrick H.

Fisk

\section{\#POLÍTICA
Acerca \\ de la \\ crisis \\ social \\ Chile \\ 2019}

José Castillo

Arancibia

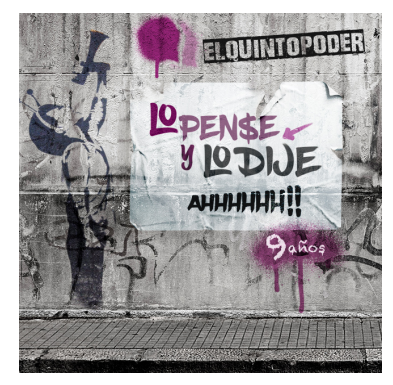

Cabe señalar, que a diferencia del estallido social ocurrido hace prácticamente nueve meses, en esta ocasión la crisis económica generada a raíz de las consecuencias del COVID 19 y la imposibilidad de una política económica eficaz para contrarrestar los efectos de la pandemia, han generado que no solamente los sectores más vulnerables de la población se encuentren en una situación crítica de subsistencia, sino que también la clase media de este país, que en parte fue la que con su voto inclinó ${ }^{\circ}$ la balanza a favor del entonces candidato Piñera para convertirse nuevamente en Presidente de la República.

Ante este escenario, la ciudadanía al no percibir una política de Estado que pueda sosteniblemente constituirse en un salvataje económico ha optado quizás por el único medio de presión efectivo con el que cuentan, que es la movilización ciudadana masiva, la cual es un abierto desafío no solo a las fuerzas de orden, sino que también a la situación sanitaria actual.

En este sentido, es imposible no hacer un paralelo con nuestra propia historia y comparar la situación actual con las protestas masivas ocurridas durante la dictadura militar a raíz de la crisis de la deuda, en la cual al igual que hoy las ollas comunes y la cesantía golpeaban con especial rudeza a la población nacional.

Si bien existen diferencias en relación al contexto político en que se gatillaron estos escenarios, existe una constante respecto a que cuando el hambre y la desesperación se apodera de sectores amplios de la población como está ocurriendo en este minuto y ocurrió en los años ochenta, la lucha por la 
sobrevivencia estará por encima de las estructuras de gobierno vigentes, $\mathrm{y}$ en un contexto democrático el gobierno de turno puede ver amenazada su capacidad de gobernabilidad y permanencia en el poder.

Durante la década de los ochenta, la dictadura de Pinochet se mantuvo en el poder durante el periodo de crisis económica, en base al uso de una política de terrorismo de Estado, que generó profundas heridas irreparables en nuestra sociedad y una fractura social que se mantiene hasta hoy.

En 2020 la administración Piñera y el poder legislativo, pueden elegir entre generar un clima de obstruccionismo entre ambos poderes del Estado, que finalmente no genere soluciones concordadas entre los distintos sectores políticos y satisfacer de las necesidades de la ciudadanía, poniendo en claro riesgo la subsistencia de esta administración de gobierno y/o sistema democrático, o pueden elegir el cambio de los acuerdos con tal generar políticas públicas que respondan efectivamente a las urgentes necesidades de la población y de esta manera intentar regenerar las relaciones con la ciudadanía, las cuales son claves para la gobernabilidad.

Durante los próximos días, las acciones y decisiones de los diferentes poderes del Estado son claves no solamente para la estabilidad democrática, sino que para también para salvar a millones de compatriotas del flagelo de la pobreza y el hambre.

El futuro, nos dirá cuál fue el camino por el cual las autoridades políticas han optado, en este momento crucial de la historia republicana.

\section{TAGS: \#HAMBRE CRISIS SOCIAL}

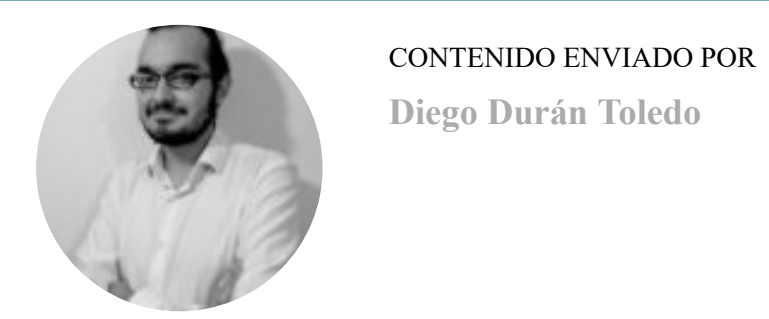

Administrador Público, Magíster en Gobierno y Gerencia Pública. Académico de la Facultad de Ciencias Sociales y del Grupo de Investigación Unidad de 
